\title{
ARMAZENAMENTO DE GOIABAS 'PALUMA' SOB REFRIGERAÇÃO E EM CONDIÇÃO AMBIENTE, COM E SEM TRATAMENTO COM CERA DE CARNAÚBA ${ }^{1}$
}

\author{
VALTEMIR GONÇALVES RIBEIRO², JOSTON SIMÃO DE ASSIS 3 , FRANKLIN FREITAS SILVA ${ }^{4}$, \\ PEDRO PAULO XIMENES SIQUEIRA ${ }^{4}$, CLÉSIO PIONORIO PEREIRA VILARONGA ${ }^{4}$
}

\begin{abstract}
RESUMO - Objetivou-se com o presente trabalho avaliar os efeitos de coberturas de cera de carnaúba Premium citrus ${ }^{\circledR}$ na conservação de goiabas 'Paluma', armazenadas sob refrigeração e em condição ambiente, pelo período de 12 dias. As características avaliadas foram perda de massa, deterioração, teores de sólidos solúveis totais (SST), acidez titulável (AT), teor de ácido ascórbico, clorofila total e firmeza da polpa. Revestimento com cera de carnaúba diminuiu a perda de massa e a degradação de clorofila das goiabas, contudo sua aplicação propiciou aumento de vida útil apenas para as frutas mantidas sob condição ambiente.
\end{abstract}

Termos para indexação: Psidium guajava, amadurecimento, pós-colheita.

\section{STORAGE OF GUAVAS 'PALUMA' UNDER REFRIGERATION AND AT ENVIRONMENTAL CONDITIONS, WITH COATED AND UNCOATED FRUITS WITH CARNAUBA WAX}

\begin{abstract}
The objective of this study was to evaluate the effect of carnaúba wax Premium citrus ${ }^{\circledR}$ on the shelf-life and quality of guavas 'Paluma', storage in a chamber with controlled temperature and storage at environmental conditions, for twelve days. The characteristics available were the fresh weight loss, total rottenness percentage, soluble solids content, tritable acidity, ascorbic acid content, and total chlorophyll of the peel and firmness of the pulp. Coatings with waxes decrease the fresh weight loss and degradation of chlorophyll of the guavas, however, its application applied to shelf life only to fruit storage at environmental conditions.
\end{abstract}

Index Terms: Psidium guajava, ripening, post harvest.

\section{INTRODUÇÃO}

O Brasil é um dos maiores produtores mundiais de goiaba (Psidium guajava L.), tendo produzindo em 2000 cerca de 300 mil toneladas. Contudo, neste período, exportou apenas $0,06 \%$ da produção (Choudhury et al., 2001). A alta perecibilidade da fruta, que, segundo Mowlah \& Itoo (1982), possui vida-de-prateleira máxima de oito dias, é um dos maiores problemas enfrentados para a sua comercialização in natura.

Apesar de a qualidade das frutas estar associada ao manejo e às condições climáticas durante a fase da produção, práticas que retardem os processos de amadurecimento e senescência após a colheita são as mais empregadas para a conservação (Chitarra \& Chitarra, 1990).

A goiaba é um fruto climatérico (Srisvastava \& Narasimhan, 1967) e, por assim ser, possui clara transição entre o crescimento e a senescência, caracterizada pelo aumento da atividade respiratória e da biossíntese de etileno (Rodhes, 1980).

As coberturas comestíveis têm recebido bastante atenção de pesquisadores nos últimos anos, graças, principalmente, às suas propriedades de barreira nas trocas gasosas e na melhoria da aparência, da integridade estrutural e propriedades mecânicas dos alimentos (Kester \& Fennema, 1986; Manica et al., 2000).

São diversas as possíveis aplicações dos revestimentos comestíveis, dependendo de suas características de barreira de forma que diminua as trocas gasosas com o ambiente, no caso de alimentos frescos; diminui a entrada de $\mathrm{O}_{2}$, no caso de alimentos oxidáveis; diminui a transferência de umidade, em casos de alto gradiente de umidade relativa entre o alimento e o ambiente (Cuq et al., 1995).

Bhullar \& Farmahan (1980) submeteram goiabas 'Safeda' a tratamentos com fitorreguladores associados à emulsão de cera a $6 \%$. O tratamento com cera foi o mais efetivo em retardar a taxa de amadurecimento, à perda fisiológica de massa dos frutos, e a diminuição da incidência de podridões.

Fakhouri \& Grosso (2003) estudaram o efeito de ceras comestíveis sobre a vida útil de goiabas, sendo que os tratamentos com ceras revelaram maior eficiência no controle do amadurecimento, proporcionando melhor brilho, cor e aparência, mostrando-se, ainda, eficiente na preservação das características físico-químicas.

Lutz \& Hardenburg (1968) relatam que goiabas destinadas ao consumo in natura podem ser conservadas entre $7,2-10^{\circ} \mathrm{C}$ e $90 \% \mathrm{UR}$, durante 2 a 3 semanas. Os resultados de Yagi et al. (1977) indicaram que goiabas do Sudão, armazenadas a $7,2 \pm 1{ }^{\circ} \mathrm{C}$ e $85 \pm 10 \%$ UR, por cinco semanas, mostraram pequena perda de peso fresco. A lavagem dos frutos em água corrente ou o uso de soluções desinfetantes (metabissulfito de sódio ou hipoclorito de cálcio) reduziram a incidência e a taxa de infecção por microrganismos. O recobrimento das goiabas com $10 \%$ da cera Sta fresh $\AA$ também reduziu o crescimento microbiano. Em trabalhos realizados por Oliveira \& Cereda (1999), sobre o efeito de película de mandioca a 1 e 2\%, na conservação de goiabas 'Kumagai', observaram-se aumentos na vida-de-prateleira dos frutos. A película não interferiu significativamente nos parâmetros de firmeza da polpa, acidez, $\mathrm{pH}$ e ácido ascórbico, porém o tratamento com a cera Sta fresh ${ }^{\circledR}$, também avaliada, foi o mais eficiente, promovendo maior diminuição da taxa de respiração como menor perda da massa dos frutos.

O presente trabalho objetivou avaliar a qualidade pós-colheita de goiabas 'Paluma', tratadas com e sem revestimento de cera de carnaúba e armazenadas sob condição ambiente e de refrigeração.

\section{MATERIALE MÉTODOS}

O experimento foi executado no Laboratório de Biologia Celular do Departamento de Tecnologia e Ciências Sociais (DTCS) da Universidade do Estado da Bahia (UNEB), Juazeiro-BA, entre os dias 03 e 15-04-2004.

Frutos de Psidium guajava (L.) 'Paluma', com média de 143,17g, foram colhidos quando a coloração da casca passou do estádio "verdeescuro" para "verde-claro", para, em seguida, sofrerem assepsia por 15 minutos em solução de hipoclorito de sódio a $200 \mathrm{mg} . \mathrm{L}^{-1}$. Depois de secas, as goiabas foram submetidas a aplicações de cera de carnaúba Premium citrus ${ }^{\circledR}(12,8 \%$ de sólidos totais) a $0 \%, 50 \%$ e $100 \%$ da

\footnotetext{
${ }^{1}$ (Trabalho 127/2004). Recebido: 07/10/2004. Aceito para publicação: 04/07/2005. Os autores agradecem o apoio financeiro da Fundação de Amparo à Pesquisa do Estado da Bahia (FAPESB), através do Programa para Fixação de Doutores no Estado da Bahia (PRODOC).

${ }^{2}$ Eng. Agr. Prof. Adjunto Dr., Universidade do Estado da Bahia (UNEB)/Departamento de Tecnologia e Ciências Sociais (DTCS), Câmpus III - Juazeiro-BA. Av. Edgard Chastinet s/n. CEP 48.900-000. E-Mail: valtemirgribeiro@yahoo.com.br

${ }^{3}$ Eng. Agr. Prof. Titular Pós-Dr. da UNEB-DTCS e Pesquisador da Embrapa Semi-Árido (CPATSA). E-Mail:joston@cpatsa.embrapa.br.

${ }^{4}$ Alunos do curso de Agronomia da UNEB-DTCS. Bolsistas FAPESB
} 
concentração original e, depois, foram armazenadas em caixas de papelão, não-sobrepostas, sobre bancada, à condição ambiente $\left(27 \pm 2^{\circ} \mathrm{C}\right.$ e $70 \pm 9 \%$ UR) e sob refrigeração $\left(10 \pm 1^{\circ} \mathrm{C}\right.$ e $85 \pm 5 \%$ UR)

O delineamento experimental utilizado foi o inteiramente casualizado, com 6 tratamentos e 3 épocas de avaliação. Empregaramse para as avaliações das goiabas recém-colhidas, com 6 e 12 dias de armazenamento, 4 repetições, cada uma constituída por 5 frutos. Análises diárias de perda de massa fresca e deterioração foram realizadas em lotes de 10 frutos cada.

As características avaliadas das frutas foram a perda de massa, obtida com o uso de uma balança eletrônica digital de precisão, pela diferença diária da massa inicial e final dos frutos; deterioração, determinada em função da percentagem de frutos com deteriorações na época da avaliação, identificadas a olho nu; teor de sólidos solúveis totais (SST), com uso de refratômetro manual; acidez titulável (AT), determinada de acordo com a metodologia descrita por Carvalho et al. (1990); teor de ácido ascórbico, conforme metodologia descrita pelo Instituto Adolfo Lutz (1985); clorofila total, determinada de acordo com a metodologia descrita por Engel \& Poggiani (1991); firmeza da polpa, utilizando-se de penetrômetro de marca Chatillon Gauger-R CAT 71920, com ponteira de $8 \mathrm{~mm}$ de diâmetro. A firmeza foi tomada em dois pontos opostos, localizados na região equatorial das frutas, sendo o revestimento de cera retirado juntamente com uma pequena porção da casca, com uso de uma lâmina.

Para análise estatística, os dados das variáveis de cada época foram submetidos à análise de variância (Teste F) e, as médias, comparadas pelo teste Tukey, a 5\% de probabilidade.

\section{RESULTADOS E DISCUSSÃO}

As avaliações da perda de massa das goiabas podem ser verificadas na Figura 1. Comparativamente, as frutas armazenadas sob refrigeração perderam menos massa do que as em condição ambiente, devido, principalmente, às menores temperaturas e maiores umidades relativas da câmara refrigerada. Os efeitos das concentrações de $50 \%$ e $100 \%$ de cera não diferiram entre si para a menor perda de massa das frutas, armazenadas tanto sob refrigeração, como em condição ambiente. Tratamentos de frutas com e sem cera, sob refrigeração, mantiveram as perdas de massa abaixo de $5 \%$ em até 12 dias de armazenamento, enquanto, em condição ambiente, as perdas ficaram dentro do limite de $15 \%$, estabelecido por Manica et al. (2000), por até 8 e 11 dias, para os tratamentos sem e com as concentrações de $50 \%$ ou $100 \%$ de cera, respectivamente. Jacomino et al. (2003) observaram diferenças de perdas de massa de $8,41 \%$ entre goiabas não-tratadas e tratadas com cera de carnaúba.

O surgimento de deterioração em ambiente refrigerado ocorreu no $10^{\circ}$ dia de armazenamento $(8,3 \%)$ e esteve apenas associado ao tratamento com ausência de cera (Figura 2). Para condição ambiente, os índices de deterioração entre tratamentos com e sem cera igualaram-se no $9^{\circ}$ dia de armazenamento $(33,2 \%)$. A partir de $10^{\circ}$ dia, o tratamento com ausência de cera apresentou tendência percentual crescente para esta variável. A patogenicidade causada por microrganismos, como fungos e bactérias, depende de condições adequadas para se manifestar. Portanto, a temperatura média de $10^{\circ} \mathrm{C}$ da câmara de refrigeração deve ter impedido o surgimento de doenças. Jacomino et al. (2003) e Lana \& Finger (2000) relatam que o revestimento de frutas com cera retarda o amadurecimento e a senescência, tornando-as menos suscetíveis a infecções causadas por patógenos.

Observa-se, na Tabela 1, para os teores de SST, avaliados no $6^{\circ}$ dia de armazenamento, que as médias dos tratamentos foram estatisticamente iguais, com valores próximos aos das goiabas avaliadas na época da colheita $\left(10,9^{\circ}\right.$ Brix $)$; contudo, no $12^{\circ}$ dia, os tratamentos diferiram entre si. As goiabas armazenadas sob condição ambiente e com ausência de cera foram as que apresentaram o maior teor de açúcares. Provavelmente isso se deva à maior perda de massa deste tratamento (Figura 1), aumentando, dessa forma, a concentração de SST nas frutas (Chitarra \& Chitarra, 1990), constatação também feita por Jacomino et al. (2003).

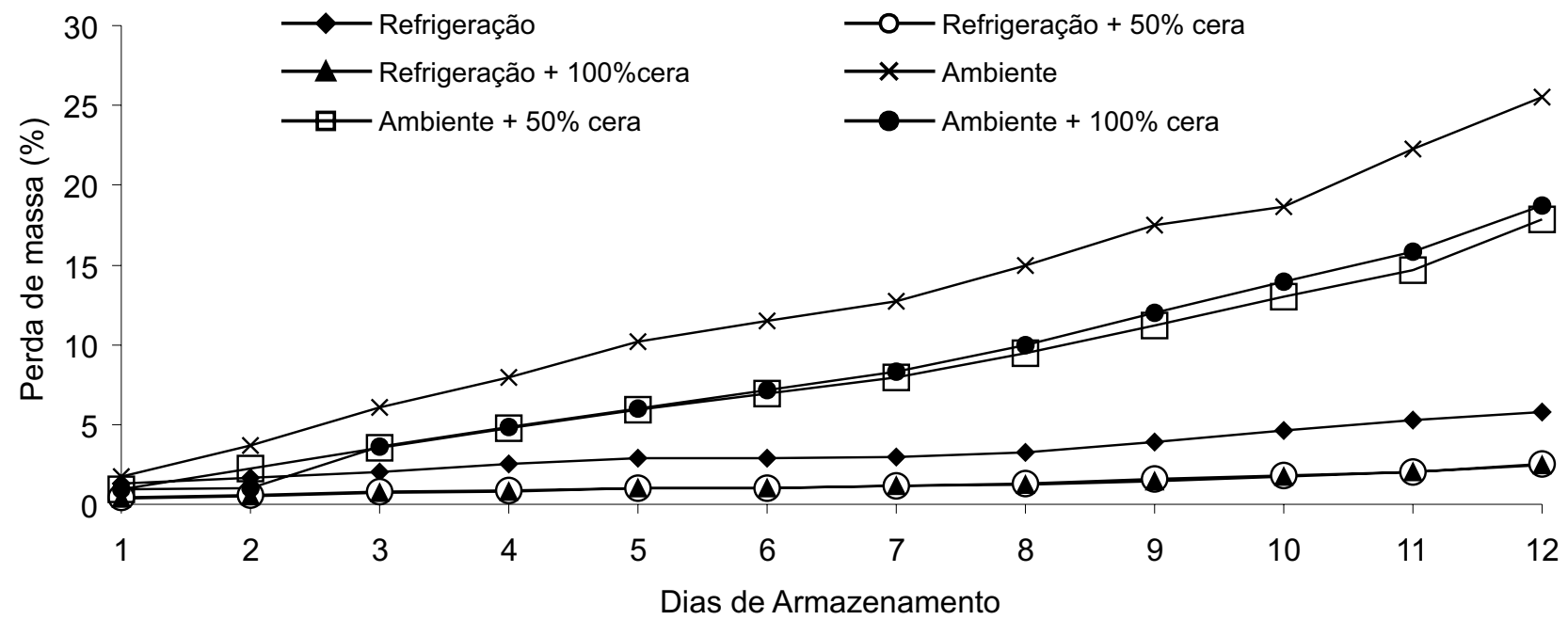

FIGURA 1 - Perda de massa de goiabas 'Paluma', com e sem revestimento de cera, armazenadas sob refrigeração e em condição ambiente.

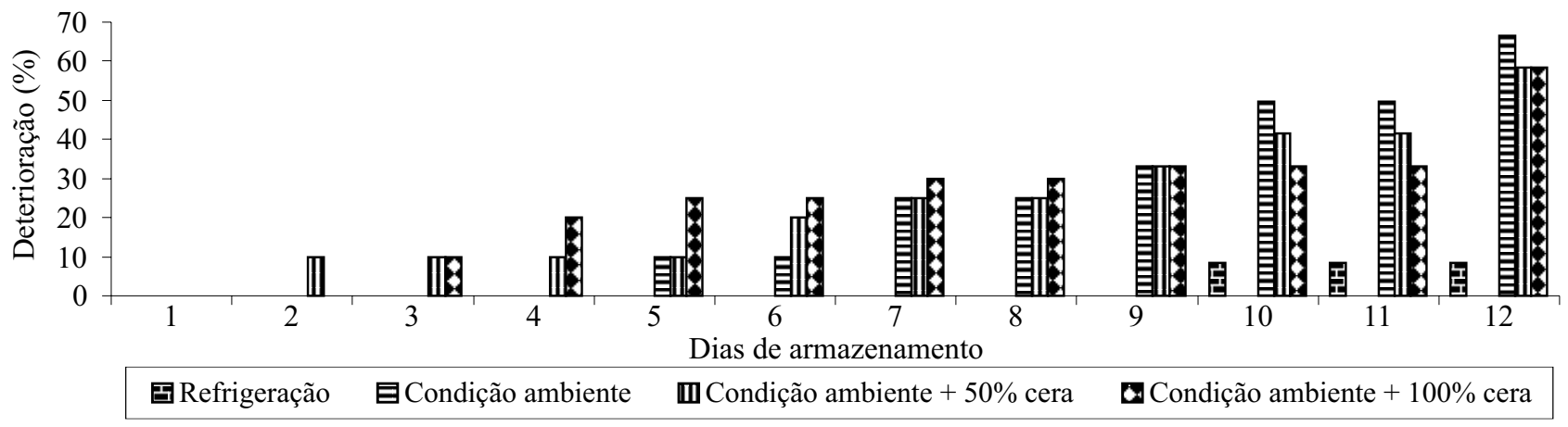

FIGURA 2 - Deterioração de goiabas 'Paluma', com e sem revestimento de cera, armazenadas sob refrigeração e em condição ambiente. 
TABELA 1 - Teores médios de sólidos solúveis totais (SST) e acidez titulável (AT) em goiabas 'Paluma', avaliadas no $6^{\circ}$ e $12^{\circ}$ dia após a colheita.

\begin{tabular}{|c|c|c|c|c|}
\hline \multirow[t]{2}{*}{ Tratamentos } & \multicolumn{2}{|c|}{$\begin{array}{c}\text { SST } \\
\left({ }^{\circ} \text { Brix }\right)\end{array}$} & \multicolumn{2}{|c|}{$\begin{array}{c}\text { AT } \\
\left(\mathrm{mg} \text { de ácido cítrico. } 100 \mathrm{~g} \text { de polpa }{ }^{-1}\right)\end{array}$} \\
\hline & $6^{\circ} \mathrm{Dia}$ & $12^{\circ} \mathrm{Dia}$ & $6^{\circ} \mathrm{Dia}$ & $12^{\circ} \mathrm{Dia}$ \\
\hline Refrigeração & 10,5 & $11,1 \mathrm{~b}$ & $0,665 \mathrm{a}$ & 0,655 \\
\hline Refrigeração $+50 \%$ cera & 10,4 & $10,9 \mathrm{~b}$ & $0,663 \mathrm{a}$ & 0,662 \\
\hline Refrigeração $+100 \%$ cera & 11,1 & $10,3 \mathrm{~b}$ & $0,656 \mathrm{a}$ & 0,664 \\
\hline Condição ambiente & 10,9 & $13,3 \mathrm{a}$ & $0,573 \mathrm{~b}$ & 0,687 \\
\hline Condição ambiente $+50 \%$ cera & 10,5 & $10,4 \mathrm{~b}$ & $0,531 \mathrm{~b}$ & 0,645 \\
\hline Condição ambiente $+100 \%$ cera & 10,8 & $11,1 \mathrm{~b}$ & $0,553 \mathrm{~b}$ & 0,775 \\
\hline $\begin{array}{ll}\text { Teste F (tratamento) } \\
\end{array}$ & n.s. & $*$ & $*$ & n.s. \\
\hline C.V. $(\%)$ & 5,70 & 8,06 & 10,57 & 13,61 \\
\hline
\end{tabular}

Sólidos solúveis totais de goiabas recém-colhidas $=10,9^{\circ} \mathrm{Brix}$

Acidez titulável de goiabas recém-colhidas $=0,923 \mathrm{mg}$ de ácido cítrico. $100 \mathrm{~g} \mathrm{de} \mathrm{polpa}^{-1}$

Médias seguidas pela mesma letra nas colunas não diferem, pelo Teste Tukey, a 5\% de probabilidade

* e n.s. = significativo a $\mathrm{P} \quad 0,05$ e não-significativo, respectivamente.

C.V. = coeficiente de variação

Ainda pela Tabela 1, verifica-se que, na data da colheita, a AT das frutas foi de $0,923 \mathrm{mg}$ de ácido cítrico. $100 \mathrm{~g} \mathrm{de} \mathrm{polpa}^{-1}$, e que seus valores reduziram no $6^{\circ}$ e $12^{\circ}$ dia de armazenamento. Essas observações são corroboradas por Jacomino et al. (2003) e por Mercado-Silva et al. (1998), que igualmente observaram redução da acidez dos frutos. Oliveira \& Cereda (1999), armazenando goiabas em ambiente com temperatura média de $25^{\circ} \mathrm{C}$, tratadas com cera de carnaúba Sta fresh ${ }^{\circledR}$, verificaram que até o $12^{\circ}$ dia de armazenamento houve um decréscimo na acidez titulável em até $0,105 \mathrm{mg}$ de ácido cítrico. $100 \mathrm{~g}$ de polpa ${ }^{-1}$, devendo-se o fato, à utilização dos ácidos orgânicos como substrato para a respiração, com o avanço da maturação dos frutos (Chitarra \& Chitarra, 1990).

Pela Tabela 2, verifica-se que as goiabas recém-colhidas possuíam 204,65 mg de ácido ascórbico. $100 \mathrm{~g}$ polpa $^{-1}$, e que, do $6^{\circ}$ para o $12^{\circ}$ dia de armazenamento, passaram de $236,33 \mathrm{mg}$ de ácido ascórbico. $100 \mathrm{~g}_{\text {de }}$ polpa $^{-1}$ para $172,87 \mathrm{mg}$ de ácido ascórbico. $100 \mathrm{~g}$ de polpa ${ }^{-1}$ e, também, que os valores diminuíram no sentido das frutas tratadas e armazenadas sob condição ambiente para as em refrigeração, bem como das menores para as maiores concentrações de cera. Jacomino et al. (2003), avaliando teores de ácido ascórbico pelo período de até 6 dias, observaram comportamentos semelhantes entre tratamentos com concentrações de cera e o controle. De acordo com Mercado-Silva et al. (1998) e Manica et al. (2000), as goiabas possuem significativa quantidade de ácido ascórbico, cujas concentrações aumentam durante as etapas de maturação e diminuem posteriormente. Estes autores relacionam este aumento inicial à maior síntese de intermediários metabólicos precursores do ácido ascórbico, e a sua posterior diminuição, à oxidação dos ácidos orgânicos durante o amadurecimento. Goiabas mantidas sob refrigeração, tratadas com cera, estiveram menos sujeitas a esses processos.

A avaliação da clorofila total (Tabela 2) demonstrou tendências de diminuição de valores com o passar do tempo de armazenamento, independentemente dos tratamentos aplicados. Tratamentos sem cera, mantidos sob refrigeração ou em condição ambiente, propiciaram maior degradação da clorofila contida na casca das frutas. Wills et al. (1981) relatam que a degradação da clorofila está associada não só a alterações dos ácidos e do pH, como também ao aumento dos processos oxidativos. Revestimentos com 50\% e $100 \%$ de cera podem ter exercido efeitos benéficos na permeabilidade da casca, alterando as trocas gasosas (Amarante \& Banks, 2001), e ao reduzir os processos oxidativos, contribuíram positivamente para a menor degradação da clorofila.

Para a variável firmeza da polpa, as médias dos tratamentos não diferiram estatisticamente ao longo dos períodos de armazenamento, porém observou-se que o tratamento com ausência de cera e sob condição ambiente apresentou valores sempre menores dos demais tratamentos. As frutas tratadas com $100 \%$ de cera e sob refrigeração foram as que mais contrastaram com as goiabas mantidas em condição ambiente e sem revestimento de cera, atingindo, respectivamente, valores de $6,86 \mathrm{~kg} / \mathrm{cm}^{2}$ e $7,39 \mathrm{~kg} / \mathrm{cm}^{2}$.

Esses resultados são semelhantes aos de Oliveira \& Cereda (1999), que, tratando goiabas com película de fécula de mandioca e armazenando-as à temperatura média ambiente de $25^{\circ} \mathrm{C}$, não verificaram diferenças significativas entre os tratamentos. Porém, são contrários aos de Jacomino et al. (2003), que, trabalhando com goiaba 'Pedro Sato', observaram variações na firmeza da polpa entre as frutas submetidas a aplicações com várias marcas de cera e a testemunha.

TABELA 2 - Teores médios de clorofila total e ácido ascórbico em goiabas 'Paluma', avaliadas no $6^{\circ}$ e $12^{\circ}$ dia após a colheita.

\begin{tabular}{|c|c|c|c|c|}
\hline \multirow[t]{2}{*}{ Tratamentos } & \multicolumn{2}{|c|}{$\begin{array}{c}\text { Ácido ascórbico } \\
\left(\mathrm{mg} .100 \mathrm{~g} \mathrm{de} \mathrm{polpa}^{-1}\right)\end{array}$} & \multicolumn{2}{|c|}{$\begin{array}{c}\text { Clorofila total } \\
\left(\mathrm{mg} .100 \mathrm{~g} \mathrm{de} \mathrm{casca}^{-1}\right)\end{array}$} \\
\hline & $6^{\circ} \mathrm{Dia}$ & $12^{\circ} \mathrm{Dia}$ & $6^{\circ} \mathrm{Dia}$ & $12^{\circ} \mathrm{Dia}$ \\
\hline Refrigeração & 212,43 a b c & 194,88 & $28,38 \mathrm{a} \mathrm{b}$ & $24,07 \mathrm{a}$ \\
\hline Refrigeração $+50 \%$ cera & 189,85 b c & 182,73 & $29,97 \mathrm{a} \mathrm{b}$ & $25,40 \mathrm{a}$ \\
\hline Refrigeração $+100 \%$ cera & $175,53 \quad c$ & 159,55 & $30,26 \mathrm{a} \mathrm{b}$ & $24,67 \mathrm{a}$ \\
\hline Condição ambiente & $236,33 \mathrm{a}$ & 172,87 & $17,85 \quad b$ & $12,64 \mathrm{~b}$ \\
\hline Condição ambiente $+50 \%$ cera & $226,75 \mathrm{ab}$ & 172,83 & $39,31 \mathrm{a} \mathrm{b}$ & $16,52 \mathrm{a} \mathrm{b}$ \\
\hline Condição ambiente $+100 \%$ cera & $208,47 \mathrm{a} \mathrm{b} \mathrm{c}$ & 187,14 & $35,24 \mathrm{a}$ & $21,47 \mathrm{a} \mathrm{b}$ \\
\hline $\begin{array}{ll}\text { Teste F (tratamento) } \\
\end{array}$ & $*$ & n.s. & $*$ & $*$ \\
\hline C.V. $(\%)$ & 7,87 & 9,21 & 10,74 & 10,63 \\
\hline
\end{tabular}

Clorofila em goiabas recém-colhidas $=31,38 \mathrm{mg} .100 \mathrm{~g} \mathrm{de}$ casca $^{-1}$

Ácido ascórbico em goiabas recém-colhidas $=204,65 \mathrm{mg} .100 \mathrm{~g}$ de polpa ${ }^{-1}$

Médias seguidas pela mesma letra nas colunas não diferem, pelo Teste Tukey, a 5\% de probabilidade.

* e n.s. = significativo a $P \quad 0,05$ e não-significativo, respectivamente.

C.V. $=$ coeficiente de variação 


\section{CONCLUSÕES}

Nas condições em que o experimento foi instalado no Vale do Submédio São Francisco, conclui-se que o uso da cera de carnaúba Premiu citrus ${ }^{\circledR}$ mantém a perda de massa da goiaba 'Paluma' em limites aceitáveis para a comercialização por até oito dias, reduzindo a degradação da clorofila contida na casca das frutas.

Sob refrigeração, o uso da cera é dispensável para aumentar a vida útil da fruta.

\section{REFERÊNCIAS}

AMARANTE, C.; BANKS, N.H. Postharvest physiology and quality of coated fruits and vegetables. Horticultural Reviews, New York, v.26, p.161-238, 2001.

BHULLAR, J. S.; FARMAHAN, H. L. Studies on the ripening and storage behavior of Safedan Guava (Psidium Guajava L.). Indian Food Packer, Calcuttá, v.34, n.4, p.5-7, 1980.

CARVALHO, C.R.L.; MANTOVANI, D.M.B.; CARVALHO, P.R.N.; MORAES, R.M.M. Análises químicas de alimentos. Campinas: ITAL, 1990. 121p. (Manual Técnico).

CHITARRA, M.I.F; CHITARRA, A.B. Pós-colheita de frutos e hortaliças: fisiologia e manuseio. Lavras: ESAL; FAEPE, 1990. 320p.

CHOUDHURY, M.M.; ARAUJO, J.L.P.; NETO, L.G.; RESENDE, J.M.; COSTA, T.S.; SCAGGIANTE, G. Goiaba: pós-colheita. Petrolina: Embrapa semi-árido, Brasília: Embrapa Informação Tecnológica, 2001. 45p. (Frutas do Brasil, 19).

CUQ, B.; GONTARD, N.; GUILBERT, S. Edible films and coatings as active layers. In: ROONEY, M.L. Active food packaging. Glasgow: Chapman \& Hall, 1995. p. 111-142.

ENGEL, V.L.; POGGIANI, F. Estudo da concentração de clorofila nas folhas e seu aspecto de absorção de luz em função do sombreamento em mudas de quatro espécies florestais. Revista Brasileira de Fisiologia Vegetal, Brasília, v.3, n.1, p.39-45, 1991.

FAKHOURI, F.M.; GROSSO, C. Efeito de coberturas comestíveis na vida útil de goiabas in natura (Psidium guajava L.) mantidas sob refrigeração. Brazilian Journal of Food Technology, Campinas, v.6, n.2, p.203-211, 2003.

INSTITUTO ADOLFO LUTZ. Normas analíticas. São Paulo: IMESP, 1985. v.1.p.46-47.
JACOMINO, A.P.; OJEDA, R.M.; KLUGE, R.A.; SCARPARE FILHO, J.A.S. Conservação de goiabas tratadas com emulsões de cera de carnaúba. Revista Brasileira de Fruticultura, Jaboticabal, v.25, n.3, p.401-405, 2003.

KESTER, J.J.; FENNEMA, O.R. Edible films and coatings: a review. Food Technology, Chicago, v.40, n.12, p.47-59, 1986.

LANA, M.M.; FINGER, F.L. Atmosfera modificada e controlada: aplicação na conservação de produtos hortícolas. Brasília: Embrapa Hortaliças, 2000. 34p.

LUTZ, J.M.; HARDENBURG, R.E. The commercial storage of fruits, vegetables and florist and nursery stocks. Baltimore: $U$. S. Dept. Agriculture, 1968. (Agriculture Handbook, 66).

MANICA, I.; ICUMA, I.M.; JUNQUEIRA, N.T.V.; SALVADOR, J.O.; MOREIRA, A.; MALAVOLTA, E. Goiaba. Porto Alegre: Cinco continentes, 2000.374p.

MERCADO-SILVA, E.; BENITO-BAUTISTA, P.; GARCIA-VELASCO, M.A. Fruit development, harvest index and ripening changes of guavas produced in central México. Postharvest Biology and Technology, Wageningen, v.30, n.2, p.294-295, 1998.

MOWLAH, G.; ITOO, S. Guava (Psidium Guajava L.) sugar components and related enzymes at stages of fruit- development a ripening. Journal of Japanese Society of Food Science and Technology, Tokyo, v.29, n.8, p.472-476, 1982.

OLIVEIRA, M.A.de; CEREDA, M.P. Efeito da película de mandioca na conservação de goiabas. Brazilian Journal of Food Technology, Campinas, v.2, p.97-102, 1999.

RODHES, M.J.C. The maturation and ripening of fruits. In: THIMANN, K.V.; ADELMAN, R.C.; ROTH, G.S. Senescence in plants. Florida: CRC Press, 1980. cap.8, p.157-205.

SRISVASTAVA, H.C.; NARASIMHAN, P. Physiological studies during the growth and development of different varieties of guava (Psidium guajava L.). Journal of Horticultural Science, Ashford, v.48, p.97104, 1967.

WILLS, R.H.H.; LEE, T.H.; GRAHAM, W.B.; HALL, E.G. Postharvest: an introduction to the physiology and handling of fruit and vegetables. Kensington: New South Wales University Press, 1981. $161 \mathrm{p}$.

YAGI, M.I.; SALIH; O.M.; SALIH, S.M. Preliminary investigation on improving the quality of guava in the Sudan. Sudan Journal Food Science Technology, Khartoum, v.9, p.11-14, 1977.(Footnotes) 